\title{
Accuracy of auscultatory blood pressure measurement with a long cuff
}

\author{
G A vaN MONTFRANS, G M A vaN DER HOEVEN, J M KAREMAKER, W WIELING, \\ A J DUNNING
}

\begin{abstract}
Intra-arterial blood pressure was compared with simultaneous auscultatory measurements in 37 subjects with a wide range of blood pressures and arm circumferences; six cuffs of various lengths and widths were used. Nineteen subjects had an arm circumference of $34 \mathrm{~cm}$ or more (mean $40 \mathrm{~cm}$ ) and the other 18 were considered to be non-obese and had a mean arm circumference of $30 \mathrm{~cm}$. With each larger cuff, in terms of bladder surface area, auscultatory blood pressure decreased a few $\mathrm{mm}$ relative to intra-arterial pressure both for systolic and for diastolic measurements. Apart from diastolic pressure measured with the two $12 \mathrm{~cm}$ wide cuffs $(12 \times 23 \mathrm{~cm}, 12 \times 30 \mathrm{~cm})$ in the obese group all other auscultatory measurements differed less than $5 \%$ from intra-arterial pressure, albeit with considerable variability among the subjects. The differences in error among measurements with the four largest cuffs in the obese group $(13 \times 30 \mathrm{~cm}$, $14 \times 30 \mathrm{~cm}, 14 \times 38 \mathrm{~cm}$, and a conical cuff) were clinically irrelevant, and there was even less to choose among all six cuffs in the non-obese subjects.

These results suggest that auscultatory blood pressure may be measured with acceptable accuracy with a single long bladdered cuff both in subjects with large arms and in subjects with normal sized arms.
\end{abstract}

\section{Introduction}

Both the length and width of the inflatable bladder in the occluding cuff are critical for accurate auscultatory measurement of blood pressure, but its optimum size remains controversial. Recommendations on bladder dimensions differ and if followed to the rule would mean choosing from three different sizes in the United States ${ }^{1}$ and two in the United Kingdom, ${ }^{2}$ though it has been suggested that a bladder which fully encircles the arm would compensate for any substantial disproportion between bladder width and arm girth. ${ }^{3}$ We have compared intra-arterial blood pressure with auscultatory measurements using six cuffs with bladders of varying length and width in order to see if one size of bladder would suffice for all adults regardless of the size of their arms.

\section{Subjects and methods}

Thirty six patients from the hypertension clinic and one normotensive volunteer aged 19-68 (mean 49) agreed to participate: On simultaneous measurement by two observers all had left to right differences in systolic or

Departments of Cardiology, Physiology, and Internal Medicine, Academic Medical Centre, University of Amsterdam, and Biomedical Instrumentation Research Unit TNO

G A VAN MONTFRANS, MD, internist

G M A VAN DER HOEVEN, BSC, technician

J M KAREMAKER, PHD, physiologist

W WIELING, $M D$, internist

A J DUNNING, MD, FACC, professor of cardiology

Correspondence to: Dr G A van Montfrans, Department of Cardiology, Academic Medical Centre B2-229, Meibergdreef 9, 1105 AZ Amsterdam, The Netherlands. diastolic pressure of less than $10 \mathrm{~mm} \mathrm{Hg}$. Arm circumference ranged from 23 to $48 \mathrm{~cm}$, with a mean of $30 \mathrm{~cm}$ in the 18 subjects with arm circumferences of less than $34 \mathrm{~cm}$ and $40 \mathrm{~cm}$ in the other 19 subjects. Intra-arterial pressure was measured in the left brachial artery and recorded with an ink jet recorder and was on average $161 / 89 \mathrm{~mm} \mathrm{Hg}$ (range $109-222 / 56-122 \mathrm{~mm} \mathrm{Hg}$ ) during the measurement period. With the subjects supine auscultatory blood pressure was measured on the right arm by one observer with the random zero sphygmomanometer and six cuffs in random order. The figure shows the sizes of the five rectangular bladders. The conically shaped bladder was 16

Bladder
size $(\mathrm{cm}) \quad 23 \times 1230 \times 1230 \times 1330 \times 1438-14$ Conical $23 \times 1230 \times 1230 \times 1330 \times 1438 \times 14$ Conical
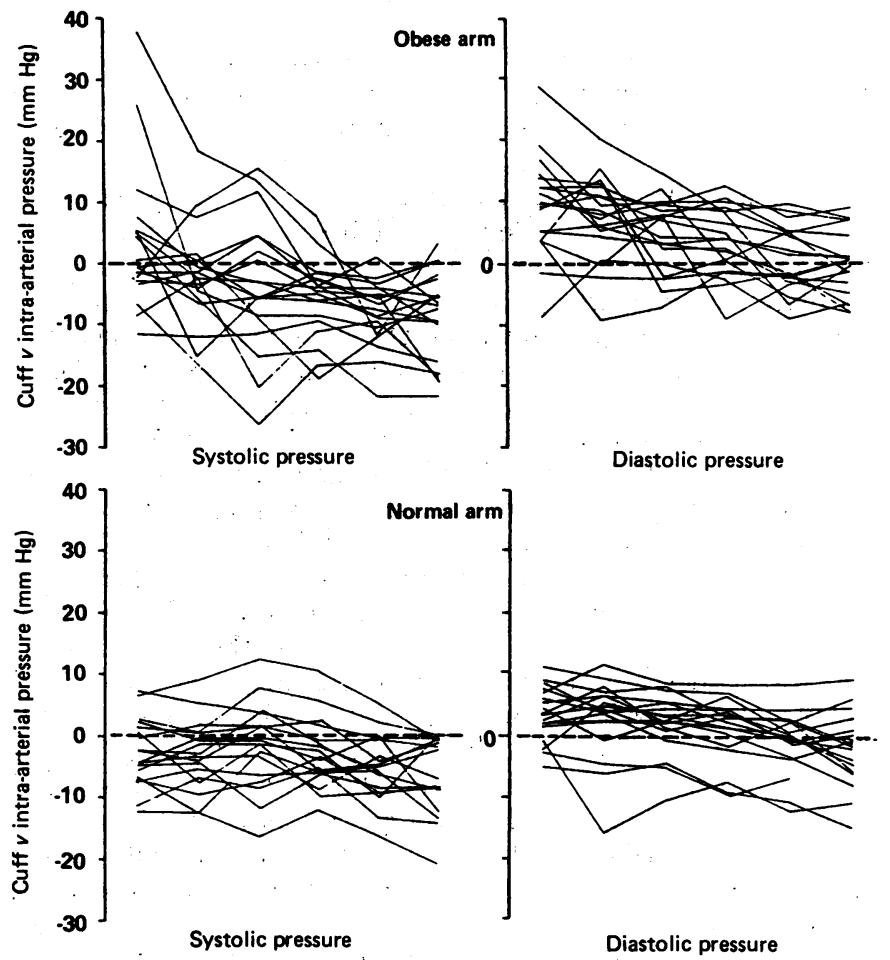

Individual differences between systolic and diastolic auscultatory (cuff) blood pressures minus intra-arterial blood pressures in 19 subjects with obese armsthat is, circumference $\geqslant 34 \mathrm{~cm}$-and 18 with normal sized arms. Figure compares six different cuffs with increasing bladder width. Each measurement point represents mean of three comparisons in one subject for one cuff.

$\mathrm{cm}$ wide and $35 \mathrm{~cm}$ long proximally and $28 \mathrm{~cm}$ distally. ${ }^{4}$ The first and las Korotkoff sounds were indicated on the paper tracing. With each cuff three measurements were made and compared with the three corresponding intraarterial waveforms and individual averages used for further calculations.

\section{Results}

The figure shows the individual differences between auscultatory and intra-arterial pressures for the six bladders. With each larger cuff, in terms of bladder area, both systolic and diastolic auscultatory pressures decreased a few $\mathrm{mm}$ relative to the intra-arterial pressure. This was more pronounced in subjects with obese arms. Mean differences were small; apart from diastolic pressure measured with the two $12 \mathrm{~cm}$ wide bladders on the obese arms 
$(23 \times 12 \mathrm{~cm},+10($ SD $8 \cdot 1) \mathrm{mm} \mathrm{Hg}, 30 \times 12 \mathrm{~cm},+7($ SD 6.9) $\mathrm{mm} \mathrm{Hg})$ all other auscultatory measurements differed less than $5 \%$ from intra-arterial pressure.

Between subject variability for the six bladders, expressed as standard deviation of the mean difference, differed significantly only for systolic pressure in subjects with obese arms $(p<0.01$; homogeneity of variance test). Diastolic variability was 4.3 to $6.4 \mathrm{~mm} \mathrm{Hg}$ in subjects with normal arms and 5.3 to $8.1 \mathrm{~mm} \mathrm{Hg}$ in those with obese arms. In the 37 subjects only for the smallest two bladders did arm circumference give positive and significant correlations with the difference between intra-arterial and auscultatory pressures $(r=0.45$ to $0 \cdot 60$ ).

\section{Discussion}

This study confirms that the differences between auscultatory and intra-arterial blood pressure readings in subjects with obese arms are acceptable when long bladdered cuffs are used, ${ }^{3}$ that these differences cannot be predicted from arm circumference, that systolic intra-arterial pressure is invariably underestimated by the cuff method, ${ }^{5}$ and that the same long bladdered cuffs estimate intraarterial pressure as accurately as the standard $23 \times 12 \mathrm{~cm}$ cuff in subjects with normal sized arms.

Which cuff, then, should be recommended? In the obese subjects differences in accuracy among the four largest cuffs were very small and clinically irrelevant, and there was even less to choose among all six cuffs in subjects with normal arms. Hence other, more practical considerations may be weighed. On the largest arms only the two longest cuffs remained properly closed without strapping during inflation, and of these the conical cuff was too wide for most arms to allow measurement without the subject undressing and is not generally available. We therefore recommend our longest rectangular cuff of $14 \times 38 \mathrm{~cm}$. Thus our findings suggest that the size of the inflatable bladder in the cuff is less critical than usually believed and support the use of only one cuff in routine blood pressure measurement in adults.

We thank Mrs $\mathrm{H}$ de Melker for technical help and $\mathrm{Mr} \mathrm{N}$ Nagelkerke for statistical advice. The conical cuff was provided by Rhone Poulenc Ltd, Amstelveen, The Netherlands. The study was supported by a grant from The Netherlands Heart Foundation.

\section{References}

1 Kirkendal WM, Feinleib M, Freis ED, Mark AL. American Heart Association report. Recommendations for human blood pressure determinations by sphygmomanometers. Circulation 1980;62:1146-55A.

2 Petrie JC, O'Brien ET, Littler WA, de Swiet M. British Hypertension Society. Recommendations on blood pressure measurement. Br Med f 1986;293:611-5.

3 King GE. Errors in clinical measurement of blood pressure in obesity. Clin Sci 1967;32:223-37.

4 Huige MC, van Vollenhoven E, Weeda HWA, Arntzenius AC. Influence of cuff size and design on indirect blood pressure measurements. Acta Cardiol 1978;33:88-90.

5 Neilsen PE, Larsen B, Holstein P, Poulsen HL. Accuracy of auscultatory blood pressure measurements in hypertensive and obese subjects. Hypertension 1983;5:122-7.

(Accepted 24 April 1987)

\title{
False positive results of tests for syphilis and outcome of pregnancy: a retrospective case-control study
}

\author{
J G THORNTON, G A FOOTE, C E PAGE, A D CLAYDEN, L A D TOVEY, J S SCOTT
}

\begin{abstract}
In a retrospective case-control study 64 women yielding a false positive result to a test for syphilis in pregnancy were compared with 128 controls individually matched for age, parity, hospital of delivery, and year of delivery. There were significantly more unsuccessful pregnancies, mainly spontaneous abortions during the first and second trimesters, among women with persistent false positive results. There was no significant difference between groups in the mean birth weights of liveborn infants.

The antibodies responsible for the false positive result may
\end{abstract}

\footnotetext{
University Department of Obstetrics and Gynaecology, Clarendon Wing, Leeds General Infirmary, Leeds LS2 9NS

J G THORNTON, MRCOG, DTM\&H, research fellow

J S SCOTT, MD, FRCOG, professor

University Department of Community Medicine, Leeds

A D CLAYDEN, BSC, PHD, senior lecturer in medical statistics

Regional Blood Transfusion Centre, Leeds

G A FOOTE, MB, MRCGP, research assistant

CE PAGE, MB, CHB, research assistant

L A D TOVEY, MD, FRCPATH, director

Correspondence to: $\mathrm{Mr}$ Thornton.
}

indicate the presence of an immunological disturbance. Women who give a false positive result should be carefully managed throughout their pregnancy.

\section{Introduction}

A false positive result to a test for syphilis is usually caused by polyclonal antiphospholipid autoantibodies including anticardiolipin and the lupus anticoagulant. ${ }^{1}$ Anticardiolipin can also be detected by a more specific and sensitive radioimmunoassay ${ }^{2}$ or enzyme linked immunosorbent assay, ${ }^{3}$ and lupus anticoagulant is detected by its in vitro effect on coagulation. Patients with autoimmune conditions such as systemic lupus erythematosus in which there is a wide range of autoantibodies have a high rate of pregnancy loss. ${ }^{4}$ The lupus anticoagulant is associated with both a high rate of pregnancy loss ${ }^{5}$ and a high frequency of false positive results to tests for syphilis. ${ }^{26}$

Although tests for syphilis have been routinely performed in pregnancy for decades, there are few data about the outcome of pregnancy in women with a false positive result. Wright and Gerken recorded 11 patients with false positive results and normal term deliveries, ${ }^{7}$ and Hare mentioned 49 cases without recording the outcome. ${ }^{8}$ In patients with systemic lupus erythematosus raised titres of anticardiolipin and abnormalities of the fetal heart rate were associated. ${ }^{9}$ Raised titres of anticardiolipin also occurred in some patients with recurrent spontaneous abortions, stillbirths, or unexplained fetal growth retardation. ${ }^{10}$ In a preliminary review a 